\title{
The Writing Questions in Literature Review--Frequently Aroused in College Students' Opening Report
}

\author{
Yan Chen $^{1}$ \\ ${ }^{1}$ College of Literature and Law, Sichuan Agricultural University, Ya'an, China \\ Correspondence: Yan Chen, College of Literature and Law, Sichuan Agricultural University, Ya'an 625014, \\ Sichuan, China. E-mail: chenyan66831@yahoo.com
}

Received: June 6, 2012 Accepted: July 3, 2012 Online Published: August 17, 2012

doi:10.5539/ass.v8n11p96 URL: http://dx.doi.org/10.5539/ass.v8n11p96

This article is sponsored by social work teaching base of Sichuan Agricultural University

\begin{abstract}
The literature review should be involved in the opening report and their thesis of college graduates for various professional graduates. Literature review in the opening report or thesis has a number of important functions, so how to write a qualified literature review in standard way is the significance that we need to focus on. The paper made a systematic sampling survey from consecutive three years in graduates' opening report, analyzed the problems existed in the process of writing literature review and gave the analyses and suggestions, in a hope of providing references in writing the literature review.
\end{abstract}

Keywords: writing questions, literature review, opening report

\section{Preface}

Literature review is an important part of the opening report and thesis in the opening report and graduation thesis, and the opening report in any one of subjects can not exist without it. Literature review is in the core of opening report and thesis and according to the practical experience in long term teaching: in each graduates' opening report and the debates, some writing problems would be come across, and those problems are repeated ones, so it is necessary to carding and summarize the problems emerged in literature review, and according to the puzzels put, giving the comparatively suggestions which undergraduates can use as reference in thesis writing.

\section{Sample Description}

The author adopted a probability sampling, systematic sampling from three consecutive years of graduates in the undergraduate thesis in the opening report of the Department of Social Work with the principles of seeking the truth from the facts. in a total of 180sample size selected 45 samples students, ie, every 4 students selected one from the total samples, there are 45 students samples all in all, then analyzed the selected samples in the topic of the literature review writing.

\section{The Relationship between Thesis Proposal and Literature Review}

Thesis proposal is a kind of scheduled explanation that the reporter gives about how to do researches on the subject that he or she selects. Generally, a thesis proposal contains: the purpose and meaning of the subject, the situation that it maintains at home and abroad, the main thoughts and results of relevant documentations; the object, content, and methods of the study, as well as all relevant quotas; a rough schedule; the stage of the preparation, and the conditions that have already been realized.

Thesis proposal for undergraduates is a kind written design which explains the feasibility of the thesis. It contains the purpose and meaning of the thesis, the situation that it maintains at home and abroad, the main problem that the thesis prepared to solve, and the content of the thesis, the schedule of the thesis, etc. Its core concept is "the main problem that the thesis prepared to solve".

While writing the thesis proposal, literature review must be firstly finished, because though literature review, one can clearly indicate the already existed opinions, conclusions, solutions, initial results that the literal works at home and abroad have put forward. Comment on the shortcomings of the above-mentioned documentation, put 
forward your own opinion and solutions, briefly explain the primary reasons.

As for whether the opinions you are prepared to argue and the methods you are going to take are feasible or not, it is just the purpose for thesis proposal. As for whether the subject you choose is worth studying, whether your opinions are novel, whether your methods are feasible, basically, they all depend on the literature review. Explain whether one's subject comply with the recent study development or whether the newest technology has been adopted and improved through comparing and commenting on review papers and those achievements that have been achieved both at home and abroad can make it easier for readers to know the meaning of the selected subject. After having read abundant Chinese and foreign documentations, the writer will abstract some points and statistics that will help prove the subject, then, he collects the information he got, analyzes it and concludes it into a technical thesis, which we call as review paper. It is a kind of scientific theses. The purpose for review paper is to reveal the recent situation a peculiar area is in. it requires the writer to introduce to the readers some detail information relevant to the subject, which must be able to reflect the newest trends, theories, principles, and technologies of this area. Hence, the forms of review paper are relatively varied. However, it usually contains four parts, they are, preface, body, conclusion and bibliography.

The purposes that a review paper must achieve are, firstly, find the space that can be studied and researched. How to realize this purpose? The proper way would be referring to as much documentations as possible. Only through reading, can we know which area has already been studied, which has not been touched yet, and which needs further exploration. According to a survey made by UNESCO (United Nations Educational, Scientific, and Cultural Organization), for those professionals who have received higher education, they generally use $20 \%$ of their time to look up documentations. All in all, the more documentation one reads, the more information one attain, the higher the quality of the review paper is. Secondly, find out the novel points. In review paper, only through reading documentation can we grasp the development condition of the studied theme, and know the new opinions, methods and theories in this area. Only when we have got enough information, and through analysis, comparison, conclusion of those information, can we judge which theories and methods are out-dated in this area, and what are theories and methods that need to be studied further, and what should be discovered. We can see the task of review paper is to comment on the shortcomings of the above-mentioned review paper achievements; to raise the opinions and solutions your thesis is going to discuss and prove; to make it clear the specific scholarly problem, i.e. the novel point that the thesis draws up. And the above two points "Search for exploratory space" and "novel points" are just the two main problems that review paper has to solve. Exploratory space indicates that some areas have the potential to be discovered, most of this kind of space hasn't been developed yet, hence, it has the value to be innovated.

Therefore, a good review paper can form a study design for thesis proposal. One of the functions of document review is that it helps to see whether our selected theme is exploratory study, so we must expand the resource of study documents. Only in this way, can we make study hypotheses, set measure index, etc. Based on what has already existed and those still haven't been explored, the author can stand in his own shoes and rely on his practical back ground to make hypotheses bravely and to prove prudently. A successful review paper should provide a strong argument for the establishment of a new topic through systematic analysis and evaluation, and solid trend prediction.

The benefits of writing a review paper are to let readers get familiar with the progress and plight of the relevant research in recent study field; to provide a question for the follow-up researchers, which is, whether further studies can find out results that are more meaningful and more significant; to give explanations for various kinds of theories and to put forward different definitions for concepts; to make possible explanations for some phenomena and behaviors depending on its role as the basis for new hypotheses and research ideas; to identify presupposition among different concepts, to understand and learn from others how to define and measure the key concepts; to improve and criticize the drawbacks of existing research, to roll out alternative research, to explore new research ways and means, to verify other relevant researches.

\section{Problems Arose in Writing of Literature Review}

When confronted with writing problems related to literature review in teaching practice, a few of the problems are more common and happen more frequently. For example, problems concerned with writing norms; problems to define concepts and relevant concepts; problems concerned about material resource and the application of those materials, problems about how to write review paper, etc. Next, we are going to have a thorough introduction. 


\subsection{Issues Related to Definition of Concepts}

Conceptual definition is the definition of the critical core words of the thesis. It requires the author to learn from the predecessors their research achievements and experiences, and raise the conception under one's own research perspective or explain clearly about the meaning of the concept in the research. Concept definition should be taken into the first account in the literature review, it demarcates the research.

Puzzles:

In the 45 samples selected from the 180 sample size, approximately $67 \%$ of the "definition" in the thesis is almost all borrowed from the existing research, very few people can define his own concept according to the actual situation and the documents. As for how to use the borrowed concepts, and the way to integrate the actual research situation are not very clear. To borrow someone else's concept and indicate the source itself is not wrong, but when the researchers quote someone else's concept, neglect the difference in connotation, extension, and the nature of the tasks and objects between those conceptions, and more serious is that the researcher did not explain the concept's meaning at all, even the phenomenon that no association between the borrowed concepts and the core notion the researcher plans to study has appeared. Among the extracted samples, there is a considerable portion in which the concept and the object does not matter much. If the concept the paper used or related concepts, especially the core concepts are not clearly defined, you can not come to literature reference.

What is more, some students did not make any definition about the core concepts in the study. For example, in the thesis proposal entitled as"90s' Graduate Employment Outlook Survey". This article begins with the 90s' college students living background, to analyze the present situation and the formation reasons of employment outlook. From the author's analysis of the object can ascertain the research content concluding two parts:"'how the employment outlook formed" and "formation reasons". But in the opening report, the author also treats the research object of the study as: "what the students' employment views, attitudes and standpoints are? what impact the environment has on 90s' college students' employment outlook?" We found that the authors did not limit the concept of research theme, therefore, it is impossible to ascertain the employment outlook means in the end. If this core concept has been defined, then the study subject is not difficult to judge.

\subsection{Suggestions}

Definition of the concept is according to research topic, through the analysis of concept which mentioned in the literature works, and with one's own research object or subject, then to make the limitation of the scope, content, objects and nature and so on. Such as talking about "teaching", it must be clear about whether it's the subject teaching, classroom teaching, or it's simple that teacher teaches his students, teachers teaching and students learning or anything else. So, particular attention should be paid to the definition of the core concepts, and it must be built on the basis of comprehensive analysis of the literature and the concrete practice.

Generally speaking, the introduction or definition of the concept has many types, so using what kind of concept, that is, why use this concept instead of others, the author should make an demonstration, in accordance with the principle of the most authoritative, the latest principles, then with one's own research practice, do a simple overview of the reasons that finally select this certain concept. If can not define, it could make an limitation according to actual research situation, to one's own definition, he still has to make a simple overview of his reason to make the so defined.

Take the" 90 s' Students Employment views Survey "as an example to talk about the problems of how to define the core concepts. First, with the help of Chinese and foreign literature works, take a look at what the meaning of "employment outlook" is in the domestic and foreign literature works. In a wide range of materials, the definitions of "employment outlook" have different angles, different levels and different points to use which concept should depend on the comparison and analysis of various definitions, and then according to the study of the object, propose the suitable definition to meet the scope of the study and the actual research. If there is no concept conforms to the research object, then the author can wholly define the concept to be discussed according to the relevant information. In this way, the definition will make people exactly understand that the object specifically refers to, avoid ambiguity, and pave the way for all aspects of the later.

\section{Literature Materials Sources}

\subsection{Problems}

The quality and quantity of the literature materials determines the mass of literature review. Found in sampling, $80 \%$ of the data is to borrow from the journals on the Net, $7 \%$ from newspapers, $13 \%$ from the writings, the rest are using the periodical literature. The sources of literature works and their quality can affect the authority of the literature, and also the literature quality problems, for example, if the literature works are not 
enough new, the amount is not enough, the range of doing desultory reading is not wide enough, all of which will lead to the problems of view and academic vision. Even in about two tenths of the reports, the worse phenomenon is although there list generous cited works in the articles, the author hadn't really used them. This is attribute to the author doesn't recognize the two parts that the function of literature works and the purpose of review clearly.

\subsection{Suggestions}

But, in so many literature materials, how can find those the authors need? This is information age, the literature retrieve much more convenient than before. And the author can find richful information. In the following databases: Chinese journal full-text data, Wanfang conference papers full-text database, Analysis database, Articles, Dissertation Full Text Database Information and Data, a scholar of the home full-text electronic books. Chinese patent database (full text), a library database search guide, CNKI data library. In addition, China's national ministries and local authorities all have a highly professional reference room. By using these databases, the author can retrieve the relevant information pertinently. Now there are:"Chinese academic journals on CD-ROM, select 3500 kinds of the core journals of the domestic Chinese and English and of professional characteristics, consists of eight albums, is China's first continuous publishing of large-scale integrated, multi-functional academic journal literature search system. The system is very convenient to use.

Faced with a vast multitude of materials, the ways we usually collect literature works are: First, through the Internet. to find the literature in a variety of databases of Network resources. Secondly, go to the library, reading room, and professional reference room, borrow or page academic writings or publications published in this year or in recent years ${ }^{[2]}$ In quoting Literature sources. Attention should be paid to these two issues:(1) novel: as much as possible to access and refer to the latest literature materials, Price index, the number of referring to published literature in recent five years should reach about $70 \%$, the higher the index, the more it can reflect the novelty of the literature review, the easier to publish or to guide new research. The development of modern science and technology is at an alarming speed, from the growth rate of various scientific publications, we can see it to doubles every 8 years, $50 \%$ of the literature will be obsolete after five years.

Thus the so-called new information should be published in recent five years. The extensive. For the same research topic, with the knowledge of historiography from ancient to modern and even contemporary dating to understand, with the help of sociological studies can comb out the point of view of the different schools at home and abroad, either we can use the anthropological knowledge, or we can also borrow the theory of the psychology to assert the objects of research topics. In short, the work to prepare materials should be multiple perspectives and various angles, so that the discussion can be extensive and profound on the same subject.

\section{How to Write Literature Review}

The literature review merely expounds the development process and the direction of research in the corresponding fields, especially development trends and the latest achievements in recent years. By comparison with the Chinese and foreign research results and the comments, stating one's topic is in line with current research and there is some progress, or indicate that has used the latest technology and improved, the purpose is to enable the reader to understand the significance of the topics further. According to this essence, and the students' own understanding of the literature review, the review in the college students' opening report is entitled as the "literature review", "Home and Abroad", the "field research", "Research in this field study Review ",domestic and international research profiles, the "Research", "Summary of the research in the field and the theoretical basis," Foreign Research "," Summary of the research literature in the field" and so on. This flourishing names are feasible in the content arrangement of the thesis proposal, it does not affect the writing content, it will not lead to unnecessary misunderstandings because of the different names, too. Although there is no misunderstanding in the name, there are a lot of problems in the literature review writing, and they are mostly concentrated on these areas:

Question 1: the standard to identify the literature works

When students writing literature review, more than $87 \%$ of the students are very easy to make errors in writing specifications, the most common mistakes are citation errors, and making very chaotic reference. In practice, errors that some students likely to make in writing is that they mark in accordance with the superscript that ordered, and also write at the back on the year. For example, to write like this: Song Xiaohui (2009) mentioned .......And some students all through mark the superscript to indicate the literature original source, such as Song Xiaohui mentioned that ...... This superscript commonly used as the reference format in published articles, it should be used with caution in the literature review. And some students directly show the author but do not indicate the time or only indicate the time without indicate the author, for example, "Kang Guihua (2011) 
believe that respect for the parties themselves..." or"Kang Guihua (2011) believe that ......",all of which are common errors of the literature review norms.

Recommendations: Literature works are the main factors in the literature review. All points of view, thoughts that students formed are related to literature works. If no literature materials, one can not conduct the literature review. If to comb out, sort out, and organize one's viewpoint without the basis of full possession of literature works, it will be difficult to write the review. In all, to draw a well literature review not only requires a certain amount of the literature works, the sources of literature should also be indicated in it, that is, the author (translator or compiler) should propose the cited view, the publish year, the publications or writings the view appeared in. To do these works is both a respect for intellectual property rights of the original author, but also a requirement of academic norms. No matter what kind of literature work you used, a book or journal, domestic or foreign, ancient or modern, all should be in accordance with the specific requirements of undergraduate thesis format. If other's view is quoted in the text, it should follow this format, that is, Song Xiaohui (Song Xiaohui, 2009) mentioned that the factors affecting the concept of employment of college students can express as following points ...... "Song Xiaohui" means you quote this author's viewpoint, the "2009" shows the statement was published in 2009. In other words, "Song Xiaohui", the author, put forward the cited view in that year, as for the detailed publications or books, the press, and other information should appear in the reference section.

\section{Question 2: A Literature Review is equivalent to the phenomenon of domestic literature review}

About 87 percent of the students who write the literature review, look up the domestic literature works, talk about the domestic situation, but rarely take the foreign research progress into account, it leads to few statements about the theories of cutting-edged and advanced. Due to no access to obtain the preface and the advanced dynamic of certain theory, would make the selected topic is somewhat outdated or redundant constructed, losing the deserved meanings of the literature review.

It should be pointed out that: the works involved in literature review do not have to include the foreign materials, it is not the purpose of the research review, but the review requires researchers to occupy all related domestic and foreign literature works, if you can not find related foreign information, it would have to say clearly the methods, the ways to check information, the amount of books or journals the researcher looked up, and finally find out that the related materials or the available information of the topic is limited to some aspect. Through the detailed data can certificate that no related materials of domestic or foreign exist really, and only in this way can prove the topics you proposed is indeed the first time to emerge and it will have a strong theoretical and practical significance.

Recommendations: the so-called "sum up" ,means to integrate a research results of a particular subject area in a certain time; "statement" is more than narration but the review and commentary, that means to have the author's own unique insights, lay stress on analysis, be good at finding problems, prominent the location, advantages, and breakthrough point of the topic; object of the review, in addition to the viewpoint, it can also be the materials and methods, etc. Domestic and international literature review is short of the comprehensive review of the literature works, it refers to base on the comprehensive collection of relevant literature, by summarizing, arranging, analyzing and identifying,to describe and comment on the research results and development of a subject or a topic. "summing up" requires to analyze comprehensively, summarize and sort out the domestic and foreign literature works, to make the material be more concise and clearer, and the level be more logical; "statement "requires a comprehensive and systematic discussion after the literature consolidating. For example, through the synthetically analysis of domestic and international information, to make an analysis and comparison of different ideas between the various schools, and then draw one's own opinions or conclusions from the comparison. According to the history development and the current situation at home and abroad, as well as the affections that other professional fields may give, to find the main trend and the law in the vertical and horizontal comparisons, to point out the several possibilities of development, and to predict the likely significant impact and possible problems, then to put forward the new research assumption and the content, and the recommended specific measures, steps and plans, as well as the possibility of the achievements.

In short, the purpose of the literature review is to penetrate the point at issue of predecessors into the author's views and write a rigorous and systematic review article.

Question 3: The phenomenon that literature review equates to plating reading notes

According to the samples in the investigation, nearly 43 percent students are inclined to write the literature review in a quite similar mode, that is, several documents are given in the first half part, and the left short part is concluded into a introspection. But also, $57 \%$ of the students use the mode of "A thinks...B thinks...C thinks, and I think..." to write the literature review. 
It is not an academic literature review under this kind of logic, but some reading notes. At first, the part of "A thinks...B thinks...C thinks...and D thinks..." belongs to documentary material collection, and "I think" is the writer's evaluation based on his analysis of the previous "xx thinks". To some degree, it can signify the meaning of literature review. However, since the writer did not sort or compare the opinions of A, B, C and D, either did he present whose idea is better and the relevant reasons, he only listed the documentary materials and rarely analyzed them, leading to "literature" and no "review". Thus it can be seen that most students have simplified "literature review" into just "literature", neglecting the core process. Virtually, literature review requires students to analyze and give their comments about the documentary materials they have adopted. (Here comment does not equal to criticism. In some papers, comments have been treated as criticism directly, this is not reasonable.) Then they should clarify their own ideas and understandings after they have explained the merits and demerits of the existing researches so far.

As we all know, literature review is the short name of reviewing related literatures and summarizing them, which means that, after collecting and reading huge amount of related materials, the achievements, existing problems and the new developing trend of the researched project (discipline, topic) should be narrated and discussed systematically and comprehensively through summary and analysis. "Summary" means to collect and analyze the related information;"review" is to evaluate the ideas extracted from the information while connecting the writer's own thoughts and practical experience. This is not to make a list of the papers the writers can find, but to build a fundament for expressing their own ideas completely on the basis of summarizing and assessing the related materials.

Suggestions:

So how exactly to write literature review? Although there is no fixed writing format or steps, but there are rules to follow in the written steps. Generally speaking, to do as the following suggestions, it will be natural to finish a qualified literature review which with comprehensive and commentary characters.

Usually, when find materials, then do reading on the basis of the data selection and classification. Information reading is to find arguments related with the theme of the thesis, and list the arguments and describe them according to the content of the topic. When all the arguments of the required documents are listed, then it is necessary to classify, and the classification is to compare the contents of different types. The comparison The process of comparison is the process of analysis, by comparison can find out the difference and the properties. The comparison needs both horizontal comparison and longitudinal comparison. The comparison can be the comparison of different theories and various schools, it can also be the comparison of study conclusions, and so on. In short, only a full range of comparison can explain the actual situation of the study object. Only by the comparison method can deeply understand the connotation of raw materials, and the review writing will be a piece of cake, and combine the author's accumulated experiences and academic insights with the content of review, penetrate the whole discussion of the related questions, put the views of others and the author's together and integrate the views into a whole naturally.

After comparison, then it should synthesize the various conclusions, that is, according to the objective laws of development, analysis of literature excerpts and deduced new discovery, new insights and new findings through comparison. It is necessary to emphasize that, "sunning up" is not the accumulation of views, enumeration or word stuffing, it must not translate the original works into rigid segments; "statement" is to review the successful points and the shortcomings of the original work, but more importantly, is to extract its essence, raise one's own view on the basis of objective analysis of master data. Review is a process of dealing with information, is the innovation of various ideas, thus, personal viewpoint should not prevail over the literature works. On the basis of review literature works, it is particularly important for professional researchers that to express their own views on the cited principles, methods, results or conclusions when to write the literature review. In reference to the point of view, we should pay attention to quote literature works of the same view with the author's, but it also need to cite other literature works of different ideas, when to express the author's own view should be with sufficient argument and objective analysis as literature review is based on a comparative review way. The final step is on the basis of $t$ review and analysis, then to raise new research directions and researching suggestions.

\section{References}

Ding, Daofang, Wen, Xieqi, \& Liu, Shushun. (1988). Medical research. Liaoning Science and Technology Press.

Xue, Shaolian. (2003). How to improve the writing skills of the medical literature review. Foreign Medical•physiological,pathological science and clinical, 2.

Zhang, Jiping. (1992). Medical research methods. Jiangsu: Jiangsu Science and Technology Press.

Zhang, Lihua. (2004). Writing research skills and methods. Degree and postgraduate education.

Zhu, Guo. (2011, January). How to write undergraduate dissertation literature review. Chifeng College (Hanwen Philosophy and Social Science), 32(1). 